\title{
Studies on Quality Characteristics on Sweetened Stirred Dahi prepared by using Honey and Flaxseed Powder
}

\section{Preveneson Dympep*, Anamika Das, Sanki Raimon Susngi, Deepak Kumar Gupta, Binod Kumar Bharti, Sristi Upadhyay and John David}

Warner College of Dairy Technology,Sam Higginbottom University of Agriculture, Technology and Sciences, Prayagraj (U.P.), India

*Corresponding author

\section{A B S T R A C T}

Keywords

Nutritional,

Therapeutic,

Sweetened,

Fortified, Honey,

Flaxseed Powder,

Antioxidant

Article Info

Accepted:

22 August 2019

Available Online:

10 September 2019
Dahi is a traditional fermented dairy product prepared by lactic acid fermentation of milk. In the present study, Flaxseed and Honey has been added to Dahi in different proportions. Trials were conducted to adjudge the most acceptable levels of Honey (6\% and 9\%) and Flaxseed powder $(3 \%, 6 \%$ and $9 \%)$ on the basis of sensory scores. Based on organoleptic scores the final optimized product contains 9\% Honey and 6\% Flaxseed Powder which was highly acceptable. The Dahi prepared without addition of Honey and Flaxseed Powder was treated as control. The optimized product contained 7\% Fat, $4.19 \%$ Protein, 0.86\% Ash, 20.82\% Carbohydrate, $32.86 \%$ Total solid. It had $0.76 \%$ Titratable Acidity, 7.12 $\mathrm{mg} / 100 \mathrm{~g}$ ascorbic acid Antioxidant activity and $5.73 \%$.Crude Fibre. Addition of Flaxseed powder increased the fibre content of Dahi.

\section{Introduction}

Dahi or Curd is a traditional fermented milk product and is nutritionally as well as therapeutically beneficial for human beings (Yadav et al., 2007).People who has a lactose intolerance syndromecan easily digest Dahi. Dahi is a good source of proteins,B vitamins and calcium which are much easier for the body to digest than when they are present in fresh milk. With the advent of health foods, Dahi is valued for controlling the growth of intestinal bacteria and incurring intestinal diseases like constipation, diarrhoea and dysentery. It is also found effective in lowering blood cholesterol. Dahi is not only popular for its therapeutic value but its nutritive value is also unique (Laxminarayana et al., 1952).Starter cultures such as Streptococcus lactis, Streptococcus diacetylactis and Streptococcus cremoris alone or in combination with or without Leuconostoc species and Lactobacillus acidophilus, Lactobacillus bulgaricus, and Streptococcus thermophilusare used for Dahi preparation (IS: 9617, 1980). 
Honey is a natural sweet, viscous substance naturally available mono-saccharides i.e., fructose and glucose. It consists of powerful antimicrobial effects against pathogenic and non-pathogenic micro-organisms (yeasts and fungi) even against those that developed resistance to many antibiotics. Honey has an antibacterial activity and is attributed both to physical factors (acidity and osmolarity) and other chemical factors (hydrogen peroxide, beeswax, volatiles and pollen). Honey is essentially a highly concentrated two sugars: dextrose $(31 \%)$ and levulose $(38 \%)$ with small amounts of at least 22 other more complex sugars. Honey also contains a good proportion of sucrose $(1.3 \%)$. Glucose and fructose are the only mono-saccharides in Honey. Honey also consists of a number of bioactive compounds viz., phenolic compounds, carotenoid and its derivatives, flavonoids, organic acids, Maillard reaction products, ascorbic acid and other compounds which function as antioxidants (Bogdanov et al.,2008).

Flaxseed or linseed (Linum usitatissimum) is an oil seed whose composition has $14 \%$ fat, $28 \%$ dietary fibers, $20 \%$ protein, $7.7 \%$ moisture, $3.5 \%$ ash and $1 \%$ simple sugars. The amount of fat in flaxseed ranges from 38 to $47 \%$. Flaxseed has a unique fatty acid profile being fairly low in saturated fatty acids and rich in ALA, the essential $\omega-3$ fatty acid which is approximately $23 \mathrm{~g}$ ALA per $100 \mathrm{~g}$. Of the total fatty acids in Flaxseed, saturated fatty acids constitute 9\%, mono-saturated fatty acids $18 \%$ and poly-unsaturated fatty acids $73 \%$.

Of the unsaturated fatty acids, $\alpha$-lineolic acid (ALA) constitutes the majority at 59\% of the total fatty acids making flaxseed one of the richest sources of the fatty acids (Bhatty, 1993;Oomah et al., 1993). Flaxseed has been considered as the source of increased interest in the field of diet and disease research due to its biologically active components including pre-biotic properties of flaxseed and in its beneficial effects on neurological and hormonal disorders, cardiovascular diseases, decreased risk of cancer, particularly of the mammary and prostate gland, antiinflammatory activity, laxative effect and osteoporosis. Dietary fibers, lignans and $\omega-3$ fatty acids present in flaxseed have a protective effect against diabetes risk (Adlercreutz, 2007). The present study aimed at studying the Physico-Chemical characteristics of Dahi when it is being incorporated with Flaxseed powder and Honey.

\section{Materials and Methods}

\section{Procurement and Collection of Raw materials}

Full cream milk, Sugar, Flaxseed, Dabur Honey was collected from local market of Prayagraj, (Uttar Pradesh) for the preparation of Sweetened Stirred Dahi. Starter Culture was collected from NCDC, NDRI, Karnal and used for preparation of Sweetened Stirred Dahi.

\section{Procedure for preparation of Sweetened Stirred Dahi}

Fresh whole milk procured from local market of Naini, Prayagraj was standardized to $6 \%$ fat and $9 \%$ MSNF. Then Sugar was added about $6 \%$ to the milk which was pre-heated to $60^{\circ} \mathrm{C}$ and homogenized. Final heat treatment $90^{\circ} \mathrm{C}$ for $10 \mathrm{mins}$, the mix is cooled to $30^{\circ} \mathrm{C}$ and inoculated with NCDC-167 culture at the rate of $2 \%$. Then the product is divided into two containers where the first container is added with $6 \%$ honey and the other with $9 \%$ Honey. The product is poured into plastic cups or bowl and incubated at $35-38^{\circ} \mathrm{C}$ for $4-5$ hours. After incubation the cups/bowl are added with Flaxseed powder according to the 
treatments i.e., $3 \%, 6 \%$ and $9 \%$ and are stirred for mixing the curd and flaxseed together. Then, the products are kept refrigerated at $5^{\circ} \mathrm{C}$ for storage.

\section{Treatment Combination}

In the present study, Six treatments were formulated viz. $\mathrm{T}_{0}, \mathrm{~T}_{1}, \mathrm{~T}_{2}, \mathrm{~T}_{3}, \mathrm{~T}_{4}, \mathrm{~T}_{5}$ and $\mathrm{T}_{6}$ where in $\mathrm{T}_{0}$ is control Sweetened Stirred Dahi $(100 \% \mathrm{D}), \mathrm{T}_{1}$ was prepared with $6 \%$ Honey and $3 \%$ Flaxseed powder $(100 \% \mathrm{D}+6 \% \mathrm{H}+$ $3 \% \mathrm{~F}), \mathrm{T}_{2}$ was prepared with $6 \%$ Honey and $6 \%$ Flaxseed powder $(100 \% \mathrm{D}+6 \% \mathrm{H}+6 \% \mathrm{~F})$, $\mathrm{T}_{3}$ was prepared with $6 \%$ Honey and $9 \%$ Flaxseed powder $(100 \% \mathrm{D}+6 \% \mathrm{H}+9 \% \mathrm{~F}), \mathrm{T}_{4}$ was prepared with $9 \%$ Honey and $3 \%$ Flaxseed Powder $(100 \% \mathrm{D}+9 \% \mathrm{H}+3 \% \mathrm{~F}), \mathrm{T}_{5}$ was prepared with $9 \%$ Honey and $6 \%$ Flaxseed Powder $(100 \% \mathrm{D}+9 \% \mathrm{H}+6 \% \mathrm{~F})$ and $_{6}$ was prepared with $9 \%$ Honey and $9 \%$ Flaxseed Powder $(100 \% \mathrm{D}+9 \% \mathrm{H}+9 \% \mathrm{~F})$.

\section{Sensory or Organoleptic Score}

The sensory evaluation of Sweetened Stirred Dahi samples was done by a panel of judge using a 9 point hedonic scale. The experienced Technical staff members of the Warner college of Dairy Technology, Sam Higginbottom University of Agriculture, Technology and Sciences, Prayagraj served as a judging team and evaluated the samples of different treatment of Sweetened Stirred Dahi. Numerical score were allocated for flavour, Body and Texture, Colour and appearances and Overall acceptability of sample.

\section{Physico-Chemical Properties}

Determination of Fat content in product was determined by Gerber method, Carbohydrates (\%) to be estimated by Lane Eynon method, SP: 18, Part XI, (1981), Total Solids content was determined as per the procedure laid down in IS: SP: 18, Part XI (1981). Moisture was determined by using an electric Hot air oven. Protein content of Sweetened Stirred Dahi was determined by using Micro Kjeldal method as per IS: SP 18 (Part XI) 1981. Titratable Acidity was measured as per method described in IS: SP 18 (Part XI) 1981. Crude fibre content was done as per AOAC (1995) Determination of Antioxidant Activity was done as per DPPH method as described by Blois (1958).

\section{Microbial Analysis}

The Coliform count, Yeast and mold count and Lactic Acid Bactria Count was estimated by as per the manual of Dairy Bacteriology ICAR (1972).

\section{Statistical analysis}

Data were analyzed using Analysis of Variance (ANOVA) and Critical Difference (C.D.) in WASP Software and excel software. The values obtained were analyzed statistically as per standard procedure. The data was analyzed statically by analysis of variance at $5 \%$ level of significance.

\section{Results and Discussion}

The present study was undertaken for Studies on quality characteristics of Sweetened Stirred Dahi prepared by using Honey and Flaxseed powder. The results obtained from the analyzed data are presented under PhysicoChemical properties, Microbiological analysis and Statistical analysis.

\section{Effect of addition of Flaxseed powder and Honey on Organoleptic Score of Dahi}

Flavour score in Sweetened Stirred Dahi samples of different treatments and control are $\mathrm{T}_{0}, \mathrm{~T}_{1}, \mathrm{~T}_{2}, \mathrm{~T}_{3}, \mathrm{~T}_{4}, \mathrm{~T}_{5}$ and $\mathrm{T}_{6}$ was found to be 7 , 7.08, 7.5, 7.24, 7.28, 7.78 and 7.24. The highest mean flavour score was recorded in 
the Sweetened Stirred Dahi sample $\mathrm{T}_{5}$ (7.78) followed by $\mathrm{T}_{2}$ (7.50), $\mathrm{T}_{4}$ (7.28), $\mathrm{T}_{6}(7.24), \mathrm{T}_{3}$ (7.24), $\mathrm{T}_{1}(7.08)$ and $\mathrm{T}_{0}(7.00)$.

Body and Texture score in Sweetened Stirred Dahi samples of different treatments and control are $\mathrm{T}_{0}, \mathrm{~T}_{1}, \mathrm{~T}_{2}, \mathrm{~T}_{3}, \mathrm{~T}_{4}, \mathrm{~T}_{5}$ and $\mathrm{T}_{6}$ was found to be 7.02, 7.18, 7.08, 6.94, 7.18, 7.08 and 6.94. The highest mean Body and Texture score was recorded in the Sweetened Stirred Dahi sample $\mathrm{T}_{1}$ (7.18) followed by $\mathrm{T}_{4}$ (7.18), $\mathrm{T}_{2}$ (7.08), $\mathrm{T}_{5}$ (7.08), $\mathrm{T}_{0}(7.02), \mathrm{T}_{3}(6.94)$ and $\mathrm{T}_{6}$ (6.94).

Colour and Appearance score in Sweetened Stirred Dahi samples of different treatments and control are $\mathrm{T}_{0}, \mathrm{~T}_{1}, \mathrm{~T}_{2}, \mathrm{~T}_{3}, \mathrm{~T}_{4}, \mathrm{~T}_{5}$ and $\mathrm{T}_{6}$ was found to be $6.96,7.38,7.48,7.28,7.38$, 7.48 and 7.28. The highest mean Colour and Appearance score was recorded in the Sweetened Stirred Dahi sample $\mathrm{T}_{5}$ (7.48) followed by $\mathrm{T}_{2}$ (7.48), $\mathrm{T}_{1}$ (7.38), $\mathrm{T}_{4}$ (7.38), $\mathrm{T}_{3}$ (7.28), $\mathrm{T}_{6}(7.28)$ and $\mathrm{T}_{0}(6.96)$.

Overall Acceptability score in Sweetened Stirred Dahi samples of different treatments and control are $\mathrm{T}_{0}, \mathrm{~T}_{1}, \mathrm{~T}_{2}, \mathrm{~T}_{3}, \mathrm{~T}_{4}, \mathrm{~T}_{5}$ and $\mathrm{T}_{6}$ was found to be $7.00,7.16,7.26,7.18,7.26$, 7.42 and 7.18. The highest mean Overall Acceptability score was recorded in the Sweetened Stirred Dahi sample $\mathrm{T}_{5}$ (7.42) followed by $\mathrm{T}_{2}$ (7.26), $\mathrm{T}_{4}(7.26), \mathrm{T}_{3}$ (7.18), $\mathrm{T}_{6}$ (7.18), $\mathrm{T}_{1}(7.16)$ and $\mathrm{T}_{0}(7.00)$.

Effect of addition of Flaxseed powder and Honey on Physico-Chemical Properties of Dahi

Total Carbohydrate in Sweetened Stirred Dahi samples of different treatments and control are $\mathrm{T}_{0}, \mathrm{~T}_{1}, \mathrm{~T}_{2}, \mathrm{~T}_{3}, \mathrm{~T}_{4}, \mathrm{~T}_{5}$ and $\mathrm{T}_{6}$ was found to be $11.05,17.49,17.79,18.13,20.19,20.82$ and 21.13. The highest mean Total Carbohydrate Percentage was recorded in the Sweetened Stirred Dahi sample $\mathrm{T}_{6}$ (21.13) followed by $\mathrm{T}_{5}$ (20.82), $\mathrm{T}_{4}$ (20.19), $\mathrm{T}_{3}$ (18.13), $\mathrm{T}_{2}$ (17.79), $\mathrm{T}_{1}$
(17.49) and $T_{0}$ (11.05). Similar observation were made by Sarker et al., (2018) who conducted the study on Dahi (Curd) preparation from milk with different levels of carrot (Dacus carota) juice incorporating 0\%, $5 \%, 10 \%$, and $15 \%$.This result also agrees with Munzur et al., (2004) who found that carbohydrate content of dahi was remarkably increased with addition of banana. The results indicate that, increased in proportion of Honey and Flaxseed powder increased the carbohydrates percentage of Sweetened Stirred Dahi with significant differences $(\mathrm{P}<$ $0.05)$.

Fat content in Sweetened Stirred Dahi samples of different treatments and control are $\mathrm{T}_{0}, \mathrm{~T}_{1}$, $\mathrm{T}_{2}, \mathrm{~T}_{3}, \mathrm{~T}_{4}, \mathrm{~T}_{5}$ and $\mathrm{T}_{6}$ was found to 5.90, 6.40, 7.19, 7.87, 6.24, 7.00 and 7.70. The highest mean Fat content was recorded in the Sweetened Stirred Dahi sample $\mathrm{T}_{3}$ (7.87) followed by $\mathrm{T}_{6}$ (7.70), $\mathrm{T}_{2}$ (7.19), $\mathrm{T}_{5}$ (7.00), $\mathrm{T}_{1}$ (6.40), $\mathrm{T}_{4}$ (6.24) and $\mathrm{T}_{0}$ (5.90). The results agree with the report of Rahman et al., (2016) found that Fat percent of control Dahi was somewhat higher than the Dahi. Sweetened Stirred Dahi indicates that increased in proportion of Honey and Flaxseed powder increased the fat percentage of Sweetened Stirred Dahi with significant differences $(\mathrm{P}<$ $0.05)$.

Protein content in Sweetened Stirred Dahi samples of different treatments and control are $\mathrm{T}_{0}, \mathrm{~T}_{1}, \mathrm{~T}_{2}, \mathrm{~T}_{3}, \mathrm{~T}_{4}, \mathrm{~T}_{5}$ and $\mathrm{T}_{6}$ was found to 3.39 , 3.76, 4.27, 4.76, 3.68, 4.19 and 4.66. The highest mean Protein percentage was recorded in the Sweetened Stirred Dahi sample $\mathrm{T}_{3}$ (4.76) followed by $\mathrm{T}_{6}$ (4.66), $\mathrm{T}_{2}$ (4.27), $\mathrm{T}_{5}$ (4.19), $\mathrm{T}_{1}$ (3.76), $\mathrm{T}_{4}$ (3.68) and $\mathrm{T}_{0}$ (3.39). The result agreed with the work of Islam et al., (2017) who found that plain Dahi contained a higher amount of protein than fruit Dahi. It indicates that increased in Honey and flaxseed powder, increases the protein content of Sweetened Stirred Dahi with significant 
differences $(\mathrm{P}<0.05)$. The result of ANOVA reveals that the $\mathrm{F}(\mathrm{Cal})$ value was greater than the table value of $\mathrm{F}$ Tab at $5 \%$ level of significance. Therefore, the difference was significant, indicating significant effect of treatments on protein percent of Sweetened Stirred Dahi.

Moisture content in Sweetened Stirred Dahi samples of different treatments and control are $\mathrm{T}_{0}, \mathrm{~T}_{1}, \mathrm{~T}_{2}, \mathrm{~T}_{3}, \mathrm{~T}_{4}, \mathrm{~T}_{5}$ and $\mathrm{T}_{6}$ was found to be $78.94,71.58,69.90,68.85,68.34,67.14$ and 65.60. The highest mean moisture content was recorded in the Sweetened Stirred Dahi sample $\mathrm{T}_{0}$ (78.94) followed by $\mathrm{T}_{1}$ (71.58), $\mathrm{T}_{2}$ (69.90), $\mathrm{T}_{4}$ (68.85), $\mathrm{T}_{3}$ (68.34), $\mathrm{T}_{5}(67.14)$ and $\mathrm{T}_{6}(65.60)$. The results are similar to the report ofPrakash (2016) where the moisture content was found lower in $\mathrm{T}_{3}(86.11 \%)$ followed by $\mathrm{T}_{2}(86.31 \%), \mathrm{T}_{1}(86.49 \%)$ and $\mathrm{T}_{0}(86.68 \%)$. It indicates that increased in Honey and flaxseed powder decreases the moisture content in Sweetened Stirred Dahi. The difference was significant, indicating significant effect of treatments on moisture content.

Titratable Acidity in Sweetened Stirred Dahi samples of different treatments and control are $\mathrm{T}_{0}, \mathrm{~T}_{1}, \mathrm{~T}_{2}, \mathrm{~T}_{3}, \mathrm{~T}_{4}, \mathrm{~T}_{5}$ and $\mathrm{T}_{6}$ was found to be $0.71,0.72,0.74,0.77,0.73,0.76$ and 0.78 . The highest mean Titratable Acidity was recorded in the Sweetened Stirred Dahi sample $\mathrm{T}_{6}$ (0.78) followed by $\mathrm{T}_{3}(0.77), \mathrm{T}_{5}(0.76), \mathrm{T}_{2}$ (0.74), $\mathrm{T}_{4}(0.73), \mathrm{T}_{1}(0.72)$ and $\mathrm{T}_{0}(0.71)$. The results are similar to the report of Desai et al., (2013) who found that the Titratable acidity of fruit Dahi was significantly increased due to the addition of fruit juice/pulp.

Mustafa (1997) prepared Dahi by using different types of seasonal juice and observed that acidity content of Dahi increased due to the addition of fruit juice in Dahi. Sweetened Stirred Dahi indicates that increased in proportion of Honey and flaxseed powder, Acidity percentage of sweetened stirred dahi was also increase with significant differences $(\mathrm{P}<0.05)$. Ash content in Sweetened Stirred Dahi samples of different treatments and control are $\mathrm{T}_{0}, \mathrm{~T}_{1}, \mathrm{~T}_{2}, \mathrm{~T}_{3}, \mathrm{~T}_{4}, \mathrm{~T}_{5}$ and $\mathrm{T}_{6}$ was found to be $0.71,0.76,0.77,0.85,0.86,0.91$ and 0.92. The highest mean Ash content was recorded in the Sweetened Stirred Dahi sample $\mathrm{T}_{6}(0.92)$ followed by $\mathrm{T}_{3}(0.91), \mathrm{T}_{5}$ (0.86), $\mathrm{T}_{2}(0.85), \mathrm{T}_{4}(0.77), \mathrm{T}_{1}(0.76)$ and $\mathrm{T}_{0}$ (0.71). The findings of this study agrees with the work of Mustafa (1997)and Desai et al., (2013). Both researchers found that addition of fruit juice increased the ash percentage in Dahi. The results indicates that increased in Honey and flaxseed powder increases the ash content in Sweetened Stirred Dahi. The difference was significant, indicating significant effect of treatments on ash percent.

Antioxidant Activity in Sweetened Stirred Dahi samples of different treatments and control are $\mathrm{T}_{0}, \mathrm{~T}_{1}, \mathrm{~T}_{2}, \mathrm{~T}_{3}, \mathrm{~T}_{4}, \mathrm{~T}_{5}$ and $\mathrm{T}_{6}$ was found to be $0.43,4.28,6.04,7.7,5.30,7.12$ and 8.66. The highest mean antioxidant activity content was recorded in the Sweetened Stirred Dahi sample $\mathrm{T}_{6}$ (8.6) followed by $\mathrm{T}_{3}$ (7.7), $\mathrm{T}_{5}$ (7.12), $\mathrm{T}_{2}$ (6.04), $\mathrm{T}_{4}$ (5.30), $\mathrm{T}_{1}$ (4.28) and $\mathrm{T}_{0}(0.43)$.

Similar observation were made by Srivastava et al., (2015)which revealed that the inclusion of herbs extracts in the yoghurt significantly altered the antioxidant properties of the yoghurt samples.

It indicates that increased in Honey and flaxseed powder increases the Antioxidant activity percentage with significant differences $(\mathrm{P}<0.05)$. The significant difference was further analyzed statistically to find out the C.D. between and within the different treatment combinations. The difference between the mean values was greater than the C.D. value, 0.09. Therefore, the difference was significant. 
Fig.1 Graph of average Organoleptic Score of Control and experimental sample of Sweetened Stirred Dahi

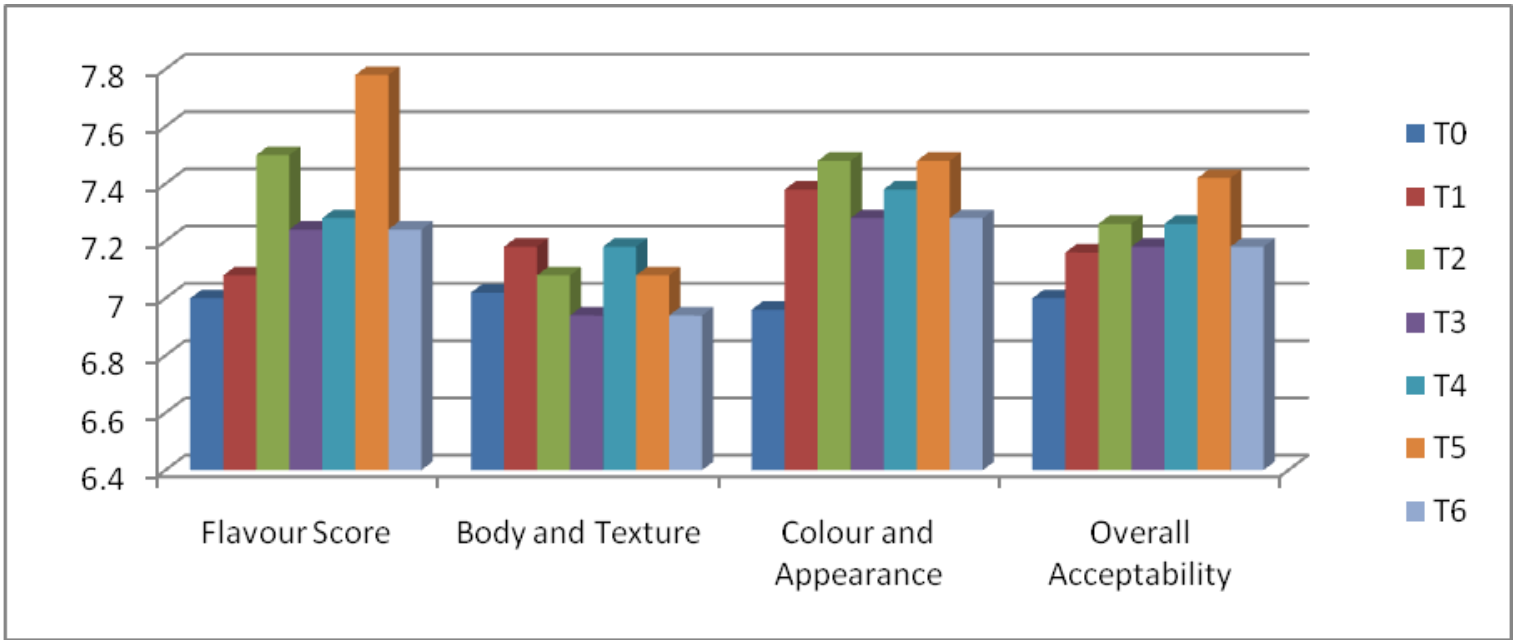

Fig.2 Graph of average Physico-Chemical analysis of Control and experimental sample of Sweetened Stirred Dahi

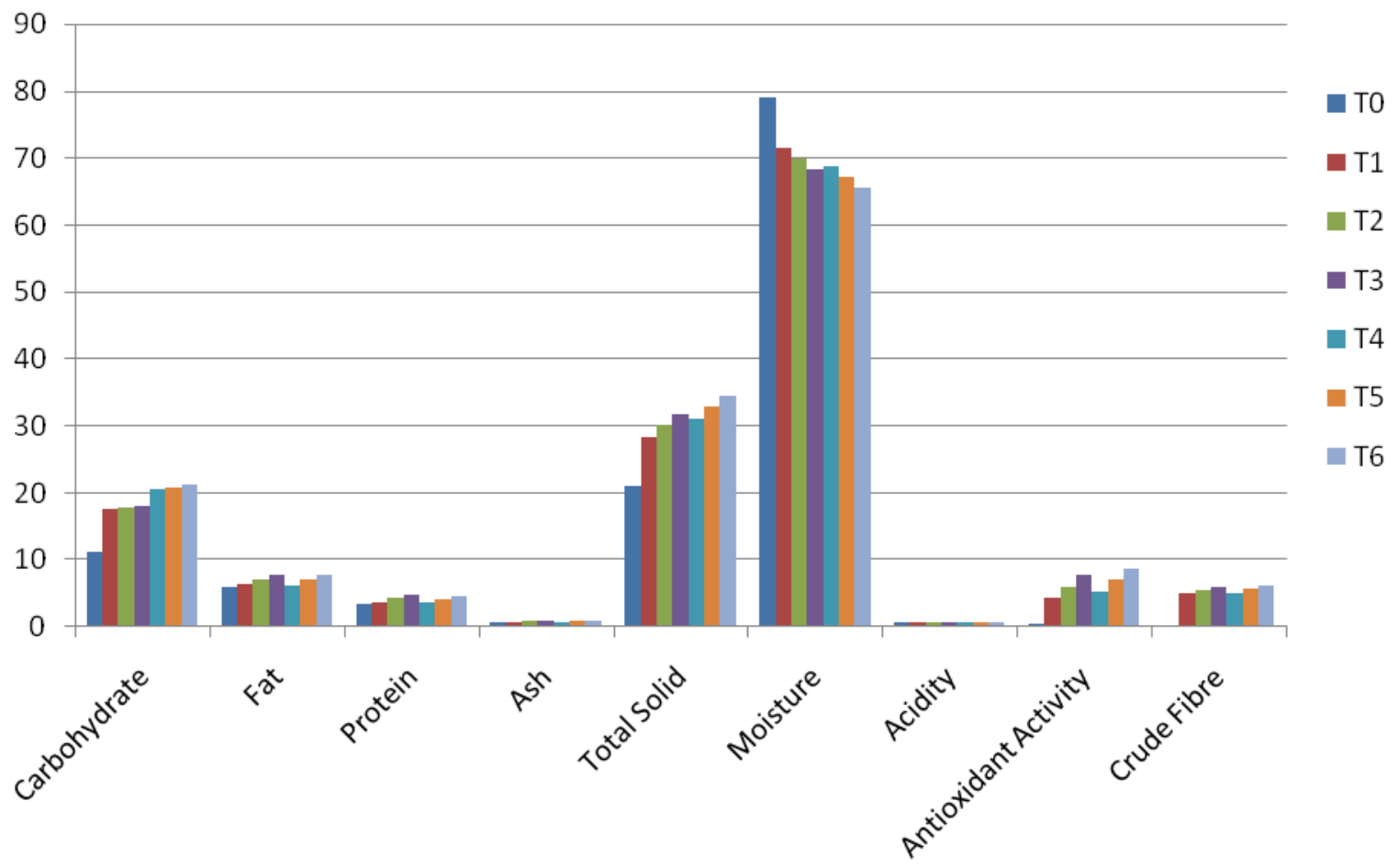

Crude Fibre content percentage in Sweetened Stirred Dahi samples of different treatments and control are $\mathrm{T}_{0}, \mathrm{~T}_{1}, \mathrm{~T}_{2}, \mathrm{~T}_{3}, \mathrm{~T}_{4}, \mathrm{~T}_{5}$ and $\mathrm{T}_{6}$ was found to be $0.17,4.99,5.46,5.97,5.05$, 5.73 and 6.09. The highest mean Crude Fibre content percentage was recorded in the
Sweetened Stirred Dahi sample $\mathrm{T}_{6}$ (6.09) followed by $\mathrm{T}_{3}(5.97), \mathrm{T}_{5}(5.73), \mathrm{T}_{2}(5.46), \mathrm{T}_{4}$ (5.05), $\quad \mathrm{T}_{1}$ (4.99) and $\mathrm{T}_{0}$ (0.17). Similar observation were made by Syama (2014) in the study of Quality Attributes of Probiotic Dahi Incorporated with Foxtail Millet where 
Crude fiber content was nil for control sample since it is devoid of millet flour.The results also indicates that increased in Honey and flaxseed powder increases crude fibre content in Sweetened Stirred Dahi with significant differences $(\mathrm{P}<0.05)$. The result of ANOVA reveals that the $\mathrm{F}$ (Cal) value was greater than the table value of $\mathrm{F}(\mathrm{Tab})$ at $5 \%$ level of significance. Therefore, the difference was significant, indicating significant effect of treatments on Crude fibre content percentage of Sweetened Stirred Dahi.

\section{Effect of addition of Flaxseed powder and Honey on Microbial analysis of Dahi}

Yeast and Mould count in Sweetened Stirred Dahi samples of different treatments and control are $\mathrm{T}_{0}, \mathrm{~T} 1, \mathrm{~T}_{2}, \mathrm{~T}_{3}, \mathrm{~T}_{4}, \mathrm{~T}_{5}$ and $\mathrm{T}_{6}$ was found to be 1.98, 2.29, 1.58, 1.09, 0.69 and 2.59. The highest mean Yeast and Mould Count was recorded in the Sweetened Stirred Dahi sample $\mathrm{T}_{6}$ (2.59) followed by $\mathrm{T}_{1}$ (2.29), $\mathrm{T}_{2}$ (2.03), $\mathrm{T}_{0}(1.98), \mathrm{T}_{3}(1.58), \mathrm{T}_{4}(1.09)$ and $\mathrm{T}_{5}$ (0.69). But Rahman et al., (2016)on this study found that the yeast count was 81.66, 142.66, $151.33,193.66$ and 217.33 per g Dahi with 0 , $5,10,15$ and $20 \%$ apple juice and the average mould count per g were 4.03, 6.36, 7.43, 8.66 and 9.33. The result of ANOVA reveals that the $\mathrm{F}(\mathrm{Cal})$ value was greater than the table value of $F(\mathrm{Tab})$ at $5 \%$ level of significance. Therefore, the difference was significant, indicating significant effect of treatments on Yeast and mould count of Sweetened Stirred Dahi. Lactic Acid Bacteria Count in Sweetened Stirred Dahi samples of different treatments and control are $\mathrm{T}_{0}, \mathrm{~T}_{1}, \mathrm{~T}_{2}, \mathrm{~T}_{3}, \mathrm{~T}_{4}$, $\mathrm{T}_{5}$ and $\mathrm{T}_{6}$ was found to be $7,11.60,15.20,18$, 10.40, 14 and 18.20. The highest mean Lactic Acid Bacteria Count was recorded in the Sweetened Stirred Dahi sample $\mathrm{T}_{6}(18.20)$ followed by $\mathrm{T}_{3}$ (18), $\mathrm{T}_{2}$ (15.20), $\mathrm{T}_{5}$ (14), $\mathrm{T}_{1}$ (11.60), $\mathrm{T}_{4}$ (10.40) and $\mathrm{T}_{0}$ (7). In Patil et al., (2015) study, it was suggested that, to have maximum therapeutic value, the fermented milk product should contain population of viable cells of probiotic culture more than $10^{6} \mathrm{cfu} / \mathrm{ml}$ at the time of consumption.

Sweetened Stirred Dahi indicates that increased in proportion of Honey it decreases yeast and mould but flaxseed powder increased the yeast and mould count of Sweetened Stirred Dahi with significant difference $(\mathrm{P}<0.05)$.

Coliform Count in Sweetened Stirred Dahi samples of different treatments and control are $\mathrm{T}_{0}, \mathrm{~T}_{1}, \mathrm{~T}_{2}, \mathrm{~T}_{3}, \mathrm{~T}_{4}, \mathrm{~T}_{5}$ and $\mathrm{T}_{6}$ was found to be $0.4,2.1,5.28,8.1,3.16,6.22$ and 9.1. The highest mean Coliform Count was recorded in the Sweetened Stirred Dahi sample $\mathrm{T}_{6}(9.1)$ followed by $\mathrm{T}_{3}(8.1), \mathrm{T}_{5}(6.22), \mathrm{T}_{2}$ (5.28), $\mathrm{T}_{4}$ (3.16), $\mathrm{T}_{1}(2.1)$ and $\mathrm{T}_{0}(0.4)$.

From the study conducted, it can be concluded that value addition of Sweetened Dahi can be done by incorporating Honey and Flaxseed powder at different ratios.

Based on Organoleptic Score thetreatment which was considered to be optimized is $\mathrm{T}_{5}$. $\mathrm{T}_{5}$ has $4.19 \%$ Protein, $7 \%$ Fat, 32.86\% Total solid, $67.14 \%$ Moisture, $0.86 \%$ Ash Content, $20.82 \%$ Carbohydrate and $0.76 \%$ Titratable Acidity. Antioxidant activity and Crude Fibre content for optimized product is $7.12 \mathrm{mg} / 100 \mathrm{~g}$ ascorbic acid and $5.73 \%$.

\section{Acknowledgement}

Authors are grateful to Dean, Warner College of Dairy Technology, SHUATS, Prayagraj for providing the necessary facilities to research work.

\section{References}

Adlercreutz, H. 2007. Lignans and human health. Criteria Rev. Clinical Laboratory Science. 44(5-6): 483-525. 
Bhatty, R. S. 1993. Further compositional analyses of flax: Mucilage, Trypsin inhibitors and hydrocyanic acid. Journal of Am. Oil Chem. Soc. 70:899-904.

Bogdanov, S., Jurendic, T., Sieber, R. and Gallmann, P. 2008.Honey for nutrition and health. Journal Am. Coll. Nutrition. 27(6): 677-689.

Desai, S. R., Toro, V. A. and Joshi, S. V. 1994.Utilization of different fruit in the manufacture of yogurt. Indian Journal of Dairy Sciences. 47: 870-874.

IS : 9617. 1980. Specification for Dahi. Indian standards Institution. New Delhi

Islam, M. T., Kabir, M. A., Rakib, M. R. H., Yesmin, M., Khan, M. Y. A., Islam, M. N. and Habib, R. 2017. Development and quality evaluation of dahi fortified with wood apple juice (Aegle marmelos). Indian Journal of Bioscience. 12(2): 157-162.

Laxminarayana, H., Nambadripad, V. K. N., Lakshmi, N. V., Nantaramiah, S. N. and Sreenivasamurthy, V. 1952. General Survey of the quality of market dahi. Indian Journal of Veterinary Science. 22(1): 13-17.

Munzur, M. M., Islam, M. N., Akhter, S. and Islam, M. R. 2004. Effect of different levels of vegetable oil for the manufacture of Dahi from skim milk. Asian Aust. Journal of Animal Science. 17: 1019-1025.

Mustafa, M. M. H. 1997. A study on the preparation of fruit Dahi (yoghurt). M.S. Thesis, Department of Dairy Science. Bangladesh Agricultural University, Mymensingh. 90-122.
Oomah, B. D. and Mazza, G. 1993. Flaxseed proteins - a review. Journal of Food Chemistry. 48: 109-114.

Patil, M. S., Dhole, P. T. and Chavan, K. D. 2015. Studies on Quality Evaluation of Probiotic Custard Apple (Annona Reticulata) Dahi. Indian Journal of Nutrition. 2(1): 109-121.

Prakash, P. V. 2016. Studies on Effect of Isabgol (Plantago Ovata) on Quality of Dahi. Department of Animal Husbandary and Dairy Science College of Agriculture. 3665.

Rahman, A., Asaduzzaman, M., Akter, M., Hassan, M. N. and Ali, M. M. 2016. Preparation of Dahi from Skim Milk Incorporating Apple Juice. International Journal of Animal Resources. 1(2): 1-8.

Sarker, M. T., Prabakusuma, A. S., Shahidul, M. and Islam, M. S. 2018. Dahi (Curd) preparation from milk with different levels of carrot (Dacus carota) juice. MOJ Food Process Technology. 6(1): 66-71.

Srivastava, P., Prasad, S. G. M., Ali, M. N. and Prasad, M. 2015. Analysis of antioxidant activity of herbal yoghurt prepared from different milk. The Pharma Innovation Journal. 4(3): 18-20.

Syama, M. A. 2014. Quality Attributes of Probiotic Dahi Incorporated with Foxtail Millet (Setaria Italica) Flour. M.Sc. Thesis. Department of Dairy Chemistry Dairy Science College. 89-109.

Yadav, H., Jain, S. and Sinha, P. R. 2007. Antidiabetic effect of probiotic dahi containing Lactobacillus acidophilus and Lactobacillus casei in high fructose fed rats. Nutrition. 23(1): 62-68.

\section{How to cite this article:}

Preveneson Dympep, Anamika Das, Sanki Raimon Susngi, Deepak Kumar Gupta, Binod Kumar Bharti, Sristi Upadhyay and John David 2019. Studies on Quality Characteristics on Sweetened Stirred Dahi prepared by using Honey and Flaxseed Powder. Int.J.Curr.Microbiol.App.Sci. 8(09): 2262-2269. doi: https://doi.org/10.20546/ijcmas.2019.809.261 